\title{
SOBERANIA DO POVO OU DOS POVOS? A DUPLA FACE DA SOBERANIA DURANTE A REVOLUÇÃO DE INDEPENDÊNCIA (RIO DA PRATA - 1808-1820)'
}

\author{
Geneviève Verdo \\ Université Paris I - Panthéon - Sorbonne
}

\section{Resumo}

A Revolução de Independência como processo político ganha pleno sentido quando estudada pelo prisma dos vínculos que uniam as cidades do antigo vice-reino, e da maneira pela qual evoluíam suas relações. Nesta perspectiva, o problema da representação e da concepção do povo soberano são chaves. Elas se apresentam por um duplo aspecto: a concepção tradicional que considerava as cidades como sujeitos da soberania, que triunfa na prática, e uma concepção mais moderna do povo, a dos dirigentes revolucionários, os quais consideravam o povo como uma entidade única e abstrata, composta por indivíduos. A história da primeira década da revolução se apresenta, em boa parte, como uma série de tentativas por parte do poder central para conciliar essas duas tendências, que têm de ser vistas como as duas faces de um mesmo projeto.

\section{Palavras-chaves}

Revolução $\bullet$ soberania $\bullet$ representação política $\bullet$ povos $\bullet$ autonomia

\section{Abstract}

In order to reveal its genuine meaning, the revolution of independence, seen as a political process, needs to be studied in the context of the links that were existing between the cities of the old viceroyalty and their evolution during this ten-year period. Considering this, the problems of political representation, and conception of the sovereign "pueblo", appear with a double aspect: the traditional view consists in considering the cities - seen as human and juridical communities - as the subject of the new sovereignty, but the revolutionary leaders tend to uphold the modern conception, considering the people in a unique and abstract way, as a community of individuals. The first decade of rioplatense revolution can be seen mostly as a series of attempts made by the central government in order to conciliate those two approaches. Those should be not seen as two separate and opposite options, but as two faces of the same political project.

\section{Keywords}

Revolution $\bullet$ sovereignty $\bullet$ political representation $\bullet$ cities $\bullet$ self-government

\footnotetext{
${ }^{1}$ Tradução de Gabriela Pellegrino Soares (Depto. História - FFLCH/USP) e Tania Gomes Mendonça (Graduanda-FFLCH/USP), do artigo publicado no original espanhol na revista Andes, Antropología e Historia. Salta, nº 13, 2002, p. 145-171.
} 


\section{Introdução}

Este trabalho pretende estudar a revolução de independência em seu aspecto político, levando em conta as questões ligadas à representação política e à reformulação da soberania. Parte do pressuposto, atualmente bem aceito, de que a cidade - vista como uma comunidade humana dotada de uma personalidade jurídica - é um dos principais atores do processo de emancipação. É inegável que foram as cidades que fizeram a revolução, levaram a cabo a guerra e optaram por este ou aquele projeto político. A isto devemos acrescentar que, na realidade, foram elas os novos sujeitos da soberanía, os quais se expressaram nos organismos representativos. Pois foram cidades - ou cidadãos vistos como membros de uma comunidade - os sujeitos que se expressaram nas assembléias populares e nos comícios, e não indivíduos propiamente ditos, entendidos como seres dotados de racionalidade e juízo singular, livres de qualquer pertenecimento corporativo.

Na raíz desta consideração, a leitura que propomos tem como fio condutor a evolução das relações entre as cidades a partir de 1808, segundo a hierarquia estabelecida no antigo vice-reino, até 1820 , momento das famosas "independências provinciais". Durante muito tempo, as autonomias provinciais foram interpretadas por alguns como a destruição de uma união nacional prévia e, por outros, como o cumprimento das promessas de Maio; na verdade, resultaram de um processo levado a cabo durante dez anos, que não foi linear nem intencional, e sim produto da combinação de uma série de fatores. Esse processo se relaciona com um problema de fundo, decorrente da própria formação da Junta em 1810 , e que tem a ver com a concepção de povo, projetado como novo sujeito da soberania. Mas este se identifica com a cidade ou com uma nova entidade a ser criada? Nesse contexto, qual o peso da hierarquia das cidades e que direito possuía a prima inter pares, Buenos Aires, de representar as demais? De que maneira esta conseguiu impor sua autoridade e manter a união da maior parte do antigo vice-reino durante una década? Estas são algumas das perguntas que orientam a reflexão a seguir.

Ao longo da primera década revolucionária, coexistem duas tendências opostas no que diz respeito ao modo de ver a soberania e a organização política do novo Estado. Uma, de corte mais "moderno", tem como ideal a centralização e a uniformização dos assuntos políticos; a outra tem como ideal a autonomia de governo. Nossa intenção é mostrar que, embora contraditórias, essas duas tendências estavam intimamente ligadas entre si. Não se trata aqui da luta entre 
centralismo e federalismo, considerados como facções opostas, encarnadas cada uma delas por figuras bem marcadas, já que essas nada mais eram do que a expressão visível e politizada do fenômeno. Na realidade, estas duas tendências existiam no seio do mesmo projeto político - não no âmbito teórico, mas pragmático -, e explicam em boa parte os vaivéns, os compromissos e as ambigüidades do regime revolucionário desses anos. Entre outras coisas, elas permitem dar sentido às formas híbridas de que se reveste a representação política, assim como às dificuldades do poder central para fixar uma forma de governo; finalmente, lançam luz sobre a fragmentação progressiva da soberania.

\section{I - Buenos Aires, cabeça do novo Estado}

\section{a. A pirâmide da obediência e suas transformações}

Com a formação do Vice-Reino do Rio da Prata, em 1776, e das intendências, em 1782, Buenos Aires adquiriu paulatinamente uma posição chave na hierarquia administrativa das cidades, constituída pelas capitais de intendências e pelas cidades que estavam subordinadas a elas.

$\mathrm{Na}$ ordem administrativa e econômica, a capital ocupou desde então um lugar destacado, sendo a sede do Vice-Reino, da Superintendência, da Aduana, assim como de uma Audiência, de um Consulado e de um Bispado. Esta função se viu reforçada pelo papel que desempenhou durante as invasões inglesas, as quais constituíram um importante episódio. Nessa ocasião, Buenos Aires se mostrou capaz de ser autônoma, já que organizou a defesa da cidade e das milícias, derrotou o vice-rei e elegeu um novo. Nessa oportunidade, pediu auxílio às províncias, que responderam com entusiasmo, fato que contribuiu para criar, ou reforçar, o vínculo existente entre as cidades do Vice-Reino. Desse modo, os diferentes povos tomaram consciência de que era necessária a solidaridade entre eles; surgiu então uma espécie de "comunidade de destino". Nesse contexto, Buenos Aires assumiu o papel de irmã mais velha, que atua como baluarte e se sacrifica pela proteção das demais. Um acontecimento significativo nesse sentido foi o pedido dirigido pelo cabildo ao Rei, em dezembro de 1807, de obtenção do título de "defensora da América do Sul e protetora dos Cabildos do Vice-Reino", título que, pouco tempo depois, lhe seria concedido. Dessa forma, a cidade foi oficialmente reconhecida como cabeça do Vice-Reino, o 
que implicou, de acordo com a concepção antiga da representação, a faculdade de tomar decisões para toda a jurisdição ${ }^{2}$.

Essa era a situação no momento da crise da Monarquia espanhola, desencadeada pela invasão da península ibérica pelos exércitos napoleônicos e pela reclusão, após algumas turbulentas semanas, do acalorado rei Fernando VII.

Não é necessário recordar aqui os pormenores dessa crise tão transcendental, nem suas repercussões na América, basta apontar seus traços principais. Em primeiro lugar, a exortação à fidelidade ao rei e à rejeição unânime a Napoleão, que motivou em todo o território da monarquia, sob o impulso da Junta Central espanhola, uma mobilização patriótica intensa. A exortação foi levada a cabo, na América, principalmente pelos curas em seus púlpitos. A "Proclamação ao clero do bispado de Córdoba", de Deán Funes, é o arquétipo desse tipo de discurso 3 . Em segundo lugar, a questão da legitimidade dos poderes que surgiu com a reorganização política da península nos anos 1808-1810 e que foi motivada pela vontade de substituir o Rei: que poder se devia reconhecer, o da Junta de Sevilla, que se auto-denominava "central", ou o de Cádiz? Por que não considerar a princesa Carlota como a regente e substituta "natural" de seu irmão Fernando? O que aconteceria se a Espanha caísse nas mãos de Napoleão?

Finalmente, em 1809, convocadas pela Junta Central de Cádiz em seu famoso decreto de 22 de janeiro, organizam-se pela primeira vez eleições na América para eleger representantes junto às Cortes. Ainda que o deputado « argentino » nunca chegasse a viajar à Espanha, durante alguns meses se produziu uma intensa mobilização nas cidades ao redor dessa eleição.

\footnotetext{
${ }^{2}$ Para uma aproximação sobre o conceito de representação política durante o período, ver GUERRA, François-Xavier. The Spanish american tradition of representation and its European roots, In: Journal of Latin American Studies, no 26, Cambridge, 1994, p. 1-35; CHIARAMONTE, José Carlos. Vieja y nueva representación: los procesos electorales en Buenos Aires, 1820-1820, In: ANNINO, Antonio (coord.): Historia de las elecciones en Iberoamérica, siglo XIX. Buenos Aires: Fondo de Cultura Económica, 1995, p. 19-63 e Ciudadanía, soberanía y representación en la génesis del estado argentino (c. 1810-1852), In: SABATO, Hilda (coord.). Ciudadanía politica y formación de las naciones. Perspectivas históricas de América Latina. México: Fondo de Cultura Económica, 1999, p. 94-116; VERDO, Geneviève. El precio del poder. Formas e usos de la representación política en la independencia argentina (1810-1821), In: Revista de Indias, Vol. LXII, nำ 225, maio-agosto, 2002, p. 385-408.

${ }^{3}$ Uma análise pormenorizada desse texto se encontra em minha tese de doutorado: Les Provinces 'désunies' du Rio de la Plata. Souveraineté et représentation politique dans l'indépendance argentine (1808-1821). París: Universidad de Paris 1, 1998, Cap. 1.
} 
Estes elementos prepararam de algum modo o que se sucederia na raíz da formação da Junta, em 1810. O acontecimento-chave das jornadas de Maio foi a transferência da soberania monárquica, representada pelo vice-rei, ao povo. Como é bem conhecido, a transferência fundamentou-se na teoria da retroversão, que propunha que em caso de impedimento do rei, a soberania devia voltar ao povo, ao qual pertencia em última instância, segundo a fórmula do "pactum translationis". Recordemos que essa mesma idéia fora usada na Espanha em 1808, quando da fundação da Junta Central depois do aprisionamento do legítimo rei e de sua substituição por José Bonaparte, considerado um usurpador ${ }^{4}$. $\mathrm{O}$ antecedente serviu à Junta de governo criada no dia 25 de maio para que se investisse de uma legitimidade absoluta, tanto com relação ao resto do ViceReino, como diante da península:

Tan libre estos como los pueblos de la Península, deben creerse con iguales facultades que aquellos, y si pudieron formar Juntas y separar á sus magistrados las capitales de España, no pude negarse igual autoridad a las de América $^{5}$

Por causa da retroversão da soberania, a Junta de Maio se impôs como a nova cabeça do vice-reino, empregando para tanto diferentes recursos. Foi assim que, pouco depois de sua formação, mandou ao Interior uma "força auxiliar" com o propósito de "ajudar" as cidades a reconhecer a mudança política e organizar eleições. Mais ainda, fez uso da prédica, com a finalidade de justificar sua própria criação e seu direito de substituir as autoridades reais, que já não eram consideradas legítimas. Nesse momento aparece a figura do mandón, caricatura do funcionário real, covarde e corrupto, no qual a Junta descarrega, entre junho e setembro de 1810, uma grande violência simbólica. A repressão exercida contra o governador de Córdoba, Juan Gutiérrez de la Concha, aparece como um paradigma do uso conjunto da força e do discurso. Isso se vê claramente no Manifesto que emite a Junta para justificar, entre outras coisas, sua ação na cidade mediterrânea:

Los pueblos pudieron erigir en la Junta Central un representante sobe-

\footnotetext{
${ }^{4}$ Cf. GUERRA, François-Xavier. Modernidad e independencias. Madrid: Mapfre, 1992.

${ }^{5}$ Manifiesto de la Junta, 9 de septiembre de 1810 In : CARRANZA, Adolfo P. (comp.). Archivo General de la República Argentina. Buenos Aires, 1894, tomo 2, p. 222. (Respeitamos a grafia original.)
} 
rano del rey ausente; disuelto aquél, reasumieron la autoridad que antes habian ejercido, para subrogarle de nuevo y el acto de esta subrogación le conferia una plenitud de facultades extensivas como antes a la conservación o remoción de aquellos magistrados que no hubiesen merecido la confianza... ${ }^{6}$

É necessário apontar, por outro lado, que a atitude de de la Concha demonstrou que o que estava em jogo não era só um conflito entre autoridades, mas também entre cidades. Na carta que manda à Junta para lhe informar que Córdoba reconheceria a autoridade do Conselho de Regência, o governador expressa claramente que essa cidade se considera tão qualificada quanto Buenos Aires para decidir sobre seu destino:

$1^{\circ}$ (...) si Buenos Ayres por capital del virreynato se ha conceptuado autorizada para quitar y poner xefes y hacerlos reconocer por el distrito independientes de España, con la capa de sostener estos dominios para el Sr Don Fernando $7^{\circ}$, Córdoba como capital de esta provincia se encuentra autorizada para sostener las autoridades legitimamente autorizadas, y mantenerse independiente de Buenos Ayres, conservando esta provincia por el Sr Don Fernando $7^{\circ}$

$2^{-}$(...) si Buenos Ayres duda de la fidelidad del Supremo Consejo de Regencia, por haberse instalado en los momentos de emigración y dispersion de la Junta Suprema, Córdoba como vé reconocida esta autoridad por la España, y potencias aliadas; no puede dudar sea deposito firme de los sagrados derechos del Monarca."7

De sua parte, a cidade de Buenos Aires, por meio de seu cabildo, apóia o esforço da Junta reclamando seu papel de baluarte e cabeça política perante as demais cidades. Defenderia, assim, seu direito de tomar decisões para salvaguardar ao conjunto do Vice-Reino em um contexto de guerra iminente, como explica aos seus soldados o chefe da expedição auxiliar ao Interior, o capitão Ortiz de Ocampo:

\footnotetext{
${ }^{6}$ Idem. O grifo é nosso.

${ }^{7}$ Carta de Juan Gutiérrez de la Concha a la Junta, junio de 1810, In: CAILLET-BOIS, Ricardo (dir.). Mayo Documental. Buenos Aires: UBA, Facultad de Filosofia y Letras, Instituto de Historia Argentina "Emilio Ravignani", 1961, v. 12, p. 258.
} 
Acordaos que es santa y justa la causa que os ha arrancado del seno de vuestra patria y de los dulces brazos de vuestras esposas y vuestros hijos, y que os ha conducido por medio de estos desiertos campos para colmaros por medio de estos glorias inmortales. La moderación y la constancia es todo cuanto tiene que recomandaros al presente vuestro General. Estad persuadidos firmemente que vuestra misión es de auxilio y no de conquista; que vais a abrazar a vuestros hermanos y no a sacrificar al fuego como a vuestros enemigos. ${ }^{8}$

Os mesmos argumentos são usados pela Junta nos documentos que envia às autoridades do Interior para ganhar sua adesão:

El pueblo de Buenos Ayres no pretende usurpar los derechos de los demas del virreinato, pretende, si, sostenerlos contra los usurpadores. Conoce que la unión reciproca de todas las provincias es el unico medio de su conservación. Conoce que para cimentar la confianza deben oirse los votos de todos y establecer un gobierno que deribe de la voluntad general de los que le han de obedecer. ${ }^{9}$

Com os acontecimentos de Maio, assistimos pois à imposição do novo poder em dois aspectos: um se relaciona com a ordem política e administrativa, ou seja, com a substituição do poder do Vice-Reino pela Junta, e o outro com a ordem hierárquica e simbólica das cidades. Daí surge a comunidade de interesses, cuidadosamente mantida durante toda a década, entre o poder central e a cidade de Buenos Aires. Essa situação produz uma confusão, da qual se serve Buenos Aires para reforçar seu prestígio. A cidade capital saberá muito bem como eximir-se quando the convier, como veremos em seguida.

O rechaço por parte de Córdoba à mudança política foi excepcional; o resto das cidades não teve dúvidas quanto a reconhecer a Junta, não só pelo temor à expedição auxiliar, mas porque viram no novo contexto uma oportunidade para promover seus desejos de reforma e para se aproximar de seu ideal político: a autonomia ou o autogoverno. A lealdade ao rei, o temor diante da incerteza

\footnotetext{
${ }^{8}$ Proclama del General Expedición Auxiliadora a su ejército, 25 de julio de 1810, In: Archivo General de la República Argentina. Op.cit., T. 2, p. 202.

${ }^{9}$ Oficio del Cabildo de Buenos Aires al de Tucumán, 29 de mayo de 1810, In: FREYRE, Ricardo J. (comp.). Tucumán en 1810. Tucumán: s.n., 1909, p. 75.
} 
e a confiança que tinham no papel diretor de Buenos Aires também pesaram em sua decisão. Ainda que aceitassem a mudança, entretanto, não deixaram de preservar a todo custo a ordem da comunidade, a que chamavam de "sua tranqüilidade". Vemos assim a cidade de Mendoza pactuar com o comandante de armas don Faustino Ansay, para que aceitasse a mudança de autoridades sem tentar se rebelar ${ }^{10}$.

Isso nos leva a pensar que as cidades aderem facilmente à nova ordem por que, em primeiro lugar, não vêem nos eventos de Maio uma verdadeira transformação e nem os sentem como uma ameaça ao equilíbrio existente; em segundo lugar, por que a Junta lhes oferece como contrapartida de sua obediência a representação política, ou seja, a faculdade para que essas comunidades expressassem suas queixas e defendessem seus interesses de maneira muito mais eficaz do que antes. A convocatória aos deputados para formar um congresso, como propõe a circular de 27 de maio, representa para as cidades o meio concreto por intermédio do qual esperam lograr o manejo de seus próprios assuntos.

É nesse momento que se define algo muito importante: a representação política aparece não só como a contrapartida da adesão ao novo poder, mas também como o elemento que lhe outorga legitimidade e cria um vínculo entre esse e as cidades. Este duplo sentido de adesão e legitimação constitui o fundamento do novo pacto político.

\section{b. As duas faces da soberania}

Durante os dois anos que se seguem à revolução, de 1811 a 1813, vemos se expressarem de uma maneira muito nítida as duas tendências opostas que definem o conceito de soberania. Prova disso é a famosa luta ocorrida em fins do ano de 1810 entre Mariano Moreno, partidário da formação de um congresso, e seus oponentes dirigidos por Cornelio de Saavedra.

A primeira destas duas tendências é encarnada, durante todo o ano de 1811, pela Junta Grande formada pelos representantes das províncias eleitos em 1810, logo incorporados à Junta de Maio. Por sua composição, esta Junta pretendia representar e ser a porta-voz de uma concepção coletiva da soberania, a soberania dos povos. Essa concepção se impõe por sua vez no Interior, a partir da reforma do sistema de governo que leva à criação das juntas provinciais no dia $10 \mathrm{de}$

\footnotetext{
${ }^{10}$ Cf. COMADRÁN RUIZ, Jorge. Mendoza en 1810, In : Tercer Congreso Internacional de Historia de América. Buenos Aires: Academia Nacional de la Historia, 1961, Tomo 6, p. 287-374.
} 
fevereiro de 1811. O decreto aparece como uma tentativa concreta para conciliar o desejo de autonomia com a eficiência de um poder centralizado: os membros das juntas deviam ser eleitos pelos cidadãos, ao passo que seu presidente era $o$ governador intendente, ainda nomeado pelo poder central.

O mesmo esforço para conciliar a soberania dos povos com a unidade do poder pode ser visto na postura que Deán Funes assume, no seio da Junta, perante o deputado de Jujuy, o cônego Gorriti, o qual defende abertamente uma concepção descentralizada do poder em nome da soberania dos povos ${ }^{11}$. Assim argumenta ao comentar o decreto de 10 de fevereiro:

... quando muchas Ciudades obedecían á un gobernador, la Capital no gozaba otra preéminencia respecto á las subalternas, que ser el asiento, ó residencia ordinaria del Gefe; pero en razón de Ciudad á Ciudad, eran iguales los derechos de la Capital, y de la subalterna, ni aquella exercía un solo acto de poder, y jurisdicción sobre estas; y ahora, á virtud de los articulos segundo, y nono, la Capital exerce actos de verdadera dominación sobre las sublaternas; el pueblo de la Capital es el que tiene derecho de elegir, y constituir exclusivamente el govierno de la Provincia; por manera, que cada vesino de la Capital viene á ser un Governador nato de la Provincia, y cada havitante de todo el distrito de la governacion un subdito natural del primero (...) Hemos proclamado la igualdad de derechos de todos los Pueblos, y está en oposición con nuestros principios un orden que exalta á unos y deprime á los mas. Es injusto, por que se falta en el punto mas esencial á los pactos con que todas las Ciudades se unieron á este govierno." 12

Se o cônego Gorriti é quem maneja a contenda dentro da Junta, fora dela vemos as províncias lutarem para conseguir mais autonomia. Este objetivo aparece claramente nas petições que enviam ao poder central como, por exemplo,

\footnotetext{
${ }^{11}$ Este episódio foi comentado por SEGRETI, Carlos. El unitarismo argentino. Notas para su estudio en la etapa 1810-1819. Buenos Aires: AZ Editora, 1991, p. 27-29 e CHIARAMONTE, José Carlos.¿Provincias o Estados? Los orígenes del federalismo rioplatense, In: GUERRA, François-Xavier (dir.). Las revoluciones hispánicas: independencias americanas y liberalismo español. Madrid: Ed. Complutense, 1995, p. 167-205.

${ }^{12}$ Escrito del Diputado de Jujuy Juan Ignacio Gorriti, 4 de Mayo de 1811, In : LEVENE, Ricardo. Las Provincias Unidas del Sud en 1811: consecuencias inmediatas de la Revolución de Mayo. Buenos Aires, s.n., 1940, Apendice documental, p. 239.
} 
a do cabildo de Mendoza, que demanda em julho de 1811 a sua separação da intendência de Córdoba ${ }^{13}$.

A segunda tendência, que poderíamos chamar de "centralista", está representada pelo Triunvirato. Este organismo, criado em setembro de 1811 pela Junta Grande, foi formado por partidários de Mariano Moreno. A partir daí, abriu-se um conflito pela conquista do poder que terminou com a dissolução da Junta, em outubro do mesmo ano. Nesse intervalo de tempo, os dois organismos trocaram cartas nas quais se lê, claramente, a concepção que cada um tinha de soberania. Diante de um Triunvirato que pretendia centralizar o poder e exercê-lo "em nome do Povo", a Junta se erige como a única e verdadeira representante da soberania dos povos:

Los pueblos nos han elegido, nos han conferido sus poderes, nos han encargado que miremos por su felicidad y bien estar, enfin, han depositado en nosotros su confianza: este es el único y verdadero título de mandar. Lo demás, querer que el mando absoluto se halle limitado á tres únicas manos, que los pueblos no han elegido, es injurioso á ellos mismos (...) Los pueblos en quienes reside originariamente el poder soberano, los pueblos unicos autores del gobierno politico, y distribuidores del poder confiado á sus magistrados, serán siempre los intérpretes de su contrato, los que puedan establecer un nuevo orden de cosas. Esos pueblos somos nosotros, desde que fuimos incorporados al gobierno."14

A oposição não reside somente na natureza, plural ou "monista" - para retomar a categorização de Pierre Rosanvallon ${ }^{15}$-, do sujeito soberano. Supõe também todo um trabalho de amadurecimento e de abstração na concepção desse sujeito. “Os povos", dos quais a Junta se pretende representante, são as cidades, as comunidades humanas e políticas que se impõem como atores centrais no processo de retroversão da soberania. São atores concretos, cuja presença na acalorada cena política é inegável. Ao contrário, o Povo soberano defendido

\footnotetext{
${ }^{13}$ Este caso como muitos outros foram estudados por Ricardo Levene en Las Provincias Unidas del Sud en 1811. Op.cit.

${ }^{14}$ Oficio de la Junta Conservadora al Gobierno Executivo, 28 de octubre de 1811, In : SAMPAY, Arturo E. Las Constituciones de la Argentina (1810-1972). Buenos Aires: Eudeba, 1975, p. 115. Itálicos nossos.

${ }^{15}$ ROSANVALLON, Pierre. La démocratie inachevée. Histoire de la souveraineté du peuple en France, XIX-XXe siècles. Paris: Gallimard, 2001.
} 
pelos morenistas é um sujeito abstrato, que resulta de um triplo trabalho - de individualização, de abstração e de projeção - que o desvincula de sua realidade concreta para apresentá-lo com um aspecto muito similar ao do antigo soberano, o rei absoluto. Nesse sentido, o Povo soberano dos morenistas é um povo "à la française", imaginado e idealizado, projetado no futuro, que fica por ser construído. A concepção radical sugere portanto toda a problemática da "construção do homem novo" ", enquanto a valorização dos "povos" se localiza no plano da regeneração, do final de um processo que começou com a conquista e a criação das cidades. A luta entre essas duas tendências no ano de 1811 revela, assim, as duas faces por meio das quais se apresenta a modernidade política.

O Triunvirato contudo, em que pese a sua concepção centralizadora do poder, tampouco pode rejeitar a representação dos povos, que figura, por exemplo, no Estatuto Provisional de novembro de 1811. Porém, durante o ano de 1812, faz muitos esforços para tirar das províncias toda a eficiência nas eleições, bem como para impedir que a assembléia reunida em abril atribua a si mesma o poder soberano ${ }^{17}$. Essa contradição só parece se resolver depois do motim de outubro, quando o novo Triunvirato convoca o que será a Assembléia do Ano Treze, na qual as províncias têm uma participação igual à de Buenos Aires ${ }^{18}$. $\mathrm{O}$ equilíbrio se restabelece, pelo menos aparentemente, porque um estudo detalhado da Assembléia mostra que esta era integrada por vários membros da Sociedade Patriótica... de Buenos Aires! Isso significa, por um lado, que a maioria das províncias tinha eleito seus representantes entre os residentes da capital e, por outro, que os membros da Sociedade Patriótica haviam criado uma rede de influência através de todo o país. Foi assim, por exemplo, que a cidade de Mendoza elegeu como representante Bernardo Monteagudo, ou que Córdoba elegeu Juan Larrea e Gervasio Posadas. Nesse momento, tudo parece indicar que as cidades delegaram à capital a função de representá-las.

Graças ao "magistério de opinião" exercido pela Sociedade Patriótica, a Assembléia do Ano Treze logrou cumprir uma tarefa importante de reformas e

\footnotetext{
${ }^{16}$ Cfr. OZOUF, Mona. L'homme régénéré. Essais sur la révolution française. Paris: Gallimard, 1989.

${ }^{17}$ Este episódio foi pouco estudado salvo nas histórias gerais. Remetemos ao nosso trabalho de tese: Les Provinces 'désunies'du Rio de la Plata. Souveraineté et représentation politique dans l'indépendance argentine (1808-1821). París: Universidad de Paris 1, 1998, cap. 2.

${ }^{18}$ Os textos de janeiro e fevereiro de 1812 que convocavam à assembléia estabeleciam uma grande desigualdade entre as cidades do interior que tinham um só representante e Buenos Aires, que além de ser representada por seus cabildantes, tinha direito a eleger cem representantes, 33 dos quais eram eleitos por sorteio.
} 
leis. Levou a cabo, na ordem do jurídico, a transferência da soberania do rei ao povo, junto com uma reforma liberal da sociedade muito parecida com aquela realizada pelas Cortes de Cádiz. A comparação não carece de interesse, pois os liberais de Cádiz, cuja influência era majoritária, foram os que impuseram na Espanha a "moderna" - quer dizer, radical - concepção de sociedade e de representação. Essa mesma ideologia se expressa nas leis da Assembléia riopratense, por exemplo no decreto de 8 de março, que postula:

Los diputados de las Provincias Unidas son diputados de la nación en general, sin perder por esto la denominación del pueblo a que deben su nombramiento, no pudiendo de ningún modo obrar en comisión." 19

Nesta citação, tudo é significativo, sobretudo a tentativa de conciliar o imaginário monista e radical com o plural. A definição dos deputados como "deputados da nação em geral" corresponde à concepção francesa, expressa por Sieyès, de representação. Quando os deputados estão reunidos em assembléia, não representam mais suas províncias, mas um conjunto que se chama Nação. Isso significa que superam, pelo simples feito de estarem juntos, suas parcialidades e interesses locais. Por essa razão, no caso francês, não têm mandato imperativo e, no caso riopratense, não têm direito de formar comissões. Supõe-se que devem perseguir, todos juntos e fundidos numa entidade de nova índole, o famoso interesse geral que não pode ser senão único e uníssono.

Contudo, vemos aqui que a tentativa de se criar uma representação verdadeiramente "nacional" (no sentido "monista"), não é finalizada: os deputados têm o nome dos povos que os elegeram e, sobretudo, conservam o comando imperativo. Quer dizer que são, ao menos em teoria, porta-vozes de suas comunidades e defensores de seus interesses. Mas, como já dissemos, este "obstáculo" está "corrigido" (a partir do ponto de vista dos morenistas) pelo pertenecimento comum dos deputados a uma sociedade que se define como criadora do "espírito público", ou seja, do conjunto de idéias inspiradas pela razão que devem conduzir o Povo à liberdade. A Sociedade Patriótica atua abertamente como "guia dos espíritos", o que repercute nas províncias mediante intensa propaganda patriótica, levada a cabo, entre outros, pelos governadores.

\footnotetext{
${ }^{19}$ El Redactor de la Asamblea, no 3, 13 de março de 1813, edição fac-sim., "La Nación", Buenos Aires, 1913, p. 9
} 


\section{II - A quebra do sistema político e a reformulação do equilíbrio}

\section{a. Buenos Aires perde o monopólio e renova o pacto}

Este equilíbrio negociado entre Buenos Aires e as cidades, fundado no reconhecimento da autoridade da capital em troca da representação política, quebra-se paulatinamente a partir de 1815 . Os eventos desse ano terão muita influência nas relações entre as cidades e o poder central. Sem entrar em pormenores, basta recordar que, sob a influência de Artigas, as províncias do Litoral decidem se subtrair do comando de Buenos Aires, e que Córdoba segue o mesmo caminho no dia 29 de março de 1815, quando substitui o governador Juan Domingo Ortiz por José Javier Díaz. Poucos dias depois, em 13 de abril, as tropas portenhas, sob a direção de Ignacio Alvarez Thomas, revoltam-se em Fontezuelas, o que provoca em Buenos Aires a queda do Diretor Alvear e sua substituição pelo general Rondeau sete dias mais tarde.

O que chama a atenção nesta mudança de poder é a maneira como Buenos Aires se esforça por reestabelecer o vínculo com as províncias. Esse é um exemplo do que apontamos antes, a saber, a cidade, para salvar seu papel reitor, retira seu apoio ao diretor deposto. A estratégia é levada a cabo pelo cabildo, representante "natural" da cidade que, como tal, assume o comando interino depois de Fontezuelas. Num Manifesto que dirige ao povo para dar uma interpretação dos eventos, descreve o Diretório como um poder faccioso, tirânico, injusto, abusivo... do qual a cidade capital, por meio de seu heróico exército, logrou escapar:

... como si la Patria fuese una ficción insignificante que pudiera sostenerse con la ruina de sus hijos, la Asamblea y el Gobierno solo proponian representar una farsa tan tragica para los Pueblos, como lucrativa a los proyectos del partido. ${ }^{20}$

Como vemos, a tática empregada é muito similar à de 1810. Já caído o antigo e detestado poder, a capital propõe às cidades um novo pacto de adesão, sobre a base de uma perfeita igualdade. Em uma circular enviada aos cabildos no dia 21 de abril, afirma-se que "Buenos Aires não aspira conservar uma pre-

\footnotetext{
${ }^{20}$ Manifiesto del Cabildo de Buenos Aires, 30 de abril de 1815, In : MAILLÉ, Agusto E. La Revolución de Mayo a través de los impresos de la época (1809-1815). Buenos Aires: s.n., 1965, v. 2, p. 413.
} 
ponderância funesta sobre os demais povos, respeita suas opiniões, sustenta seus direitos e espera ouvir sua voz para lhes confirmar que nada poderá romper os vínculos que os unem" e, falando da eleição de Rondeau, assegura que "não fez outra coisa senão colocar uma cabeça à frente do Estado para estabelecer provisoriamente a ordem e restituir a tranqüilidade. ${ }^{, 21}$ Falando assim, o texto desmente a vontade de Buenos Aires de se erigir outra vez em cabeça do corpo político. O outro meio por meio do qual se tenta repassar o pacto é o Estatuto Provisional, elaborado pela Junta de Observação e apresentado às províncias no dia 17 de maio. Mais uma vez, as cidades devem se pronunciar sobre a mudança política operada pela capital: são convidadas a reconhecer a Rondeau como o novo Diretor e jurar o Estatuto Provisional.

De fato, as cidades se pronunciam aceitando a nova ordem de coisas, ainda que com um certo receio. Deixam ver claramente que não se trata de uma adesão absoluta, e sim de uma condição sine qua non, que chamam de "o respeito aos seus direitos", ou seja, uma representação plena e inteira. Assim vemos que, por exemplo, na resposta de José Javier Díaz: se bem promete que "será fácil tudo arrumar quando se procede de boa fé e por princípios comuns e conhecidos", esse não deixa de recordar que Córdoba

bajo los auspicios del digno jefe de los orientales, había ya proclamado su independencia provincial [y que] se halla resuelto á no desistir de ella, hasta que un congreso general reunido en plena libertad (...) sancione y establezca la forma de gobierno que debera regir la América. ${ }^{22}$

Em outra parte, escreve de uma maneira ainda mais explícita:

Córdoba no teme nada de Buenos Aires, pero lo teme todo del partido que existe allí. Tampoco teme al jefe que ha elegido, pero tampoco puede prestarse á una confianza ciega, que comprometa sus derechos. ${ }^{23}$

\footnotetext{
21 "Circular del Cabildo de Buenos Aires a los cabildos, 21 de abril de 1815", Archivo Histórico de Mendoza, Periodo Independiente, Carp. 607, Fo 130 e Archivo Histórico de Tucumán, Sección Administrativa, Carp. 24, Fo 125.

${ }^{22}$ Oficios de José Javier Díaz a las autoridades de Buenos Aires, 23 y 25 de abril de 1815, In : Documentos del Archivo de San Martín, Comisión Nacional del Centenario, Coni Hermanos, Buenos Aires, 1910, t 2, p. 112-114.

${ }^{23}$ Oficio de José Javier Díaz al señor Cabildo gobernador de Buenos Aires, 8 de mayo de 1815 , Idem, p. 117
} 
A cidade de Salta, por seu lado, se pronuncia através de uma assembléia eleita que adere às condições enunciadas pelo doutor Mariano Boedo:

Que segun su parecer todo lo actuado en la capital de Buenos Aires referente al nuevo Gobierno Provisorio que ha instalado, debe ratificarse mediante que cede en beneficio de las Provincias Unidas, bajo las condiciones que en el bando se expresan interpelando al Supremo Director suplente para que active la realización y apertura del congreso en el seno de las Provincias Unidas a la mayor brevedad posible y que si no se verificase, en el término de cinco meses que se considera bastante, desde luego esta capital y su provincia dicho término pasado, quede independiente y libre para gobernarse por sí, y tratar lo que mejor tuviere por conveniente. Que el estatuto provisoiro se circule a las provincias para su ratificación, o hacer las objeciones a que haya lugar para el mejor desempeño del Director suplente. ${ }^{24}$

Para compreender a aceitação por parte das províncias de uma nova submissão a uma ordem eleita por Buenos Aires - e que antes disso, tenham sido capazes de negar-lhe sua obediência -, é necessário acrescentar um elemento muito importante, como o é o contexto da guerra. A mobilização intensa levada a cabo nas províncias desde as primeiras campanhas do Exército Auxiliar, nos anos de 1810 e 1811, havia levado ao desenvolvimento de uma organização que poderíamos qualificar de "proto-estatal". Para recrutar soldados, as autoridades tiveram que realizar censos de população, receber donativos e logo reclamar empréstimos forçosos. Para castigar os "contra-revolucionários" e os desertores, tiveram que controlar os caminhos e explorar o território da província. Para financiar, enfim, o esforço de guerra, foi necessário pagar os uniformes, os víveres, as montarias e as armas, motivo pelo qual também tiveram que criar novos impostos. Estas decisões administrativas, paralelas às vitórias militares (por exemplo as de Tucumán e Salta em 1812 e 1813) contribuíram para reforçar a identidade e o orgulho das cidades, deram-lhes consciência de sua força e evidenciaram a possibilidade de autonomia das províncias. Já em 1815, e mais ainda depois da derrota do Exército do Norte em Sipe Sipe, a impressão

${ }^{24}$ Acta Capitular de la ciudad de Salta del dia 10 de mayo de 1815, In : GÜEMES, Luis (comp.). Güemes documentado. Buenos Aires: Plus Ultra, 1978, t. 2, p. 367. 
de que não se necessitava de Buenos Aires tanto quanto antes para se defender cresceu nas cidades do Interior.

Entretanto, se é certo que já não se precisava de Buenos Aires em seu papel de cidade-baluarte, ainda fazia falta um poder central que fosse capaz de organizar o esforço militar no âmbito de todo o país. Mas, em 1815, esse poder central ainda se identificava com o grupo que conduzia os assuntos na capital. É por isso que as autoridades do Interior reconheceriam provisoriamente o novo Diretor, sem perder as esperanças na possibilidade de que se reunisse um congresso que representasse, desta vez, a soberania dos pueblos.

\section{b. Do Congresso à Constituição: tentativas de conciliação}

Este Congreso, com sede em Tucumán - o que não é casual - abre suas sessões em março de 1816. No discurso de inauguração, pode-se notar que o sentido que assume já não é, como no caso da Assembléia do ano de 1813, uma representação que pretende ser "nacional", mas antes uma conciliação, um meio termo, entre a unidade dos pueblos e a defesa de seus interesses particulares:

Es decir, pues que esta eregido el tribunal de la nación con la investidura de un derecho sagrado que proviene de la cesión que cada persona, cada familia, cada pueblo ha hecho de una porción del uso de sus derechos, revestido de una fuerza compuesta del agregado de todas las fuerzas de los miembros que la han cedido, y que reune, y concentra en sí la voluntad general formada de las voluntades particulares, a la manera de una luz viva que se enciende por la unión de muchos rayos que se dirigen a un centro." 25

As expressões sublinhadas sugerem o caráter limitado da delegação de soberania por parte dos povos à assembléia; constituem uma expressão acabada da coexistência das duas faces da soberania. De fato, a metáfora do sol traduz com exatidão o imaginário desse congresso, como também o faria a imagem de uma calecita (¿?): o eixo - o poder central - é o que permite às distintas partes - os povos - se moverem com harmonia. Essas metáforas colocam em evidência o fato de que na prática a soberania da Nação e a soberania dos povos não são

\footnotetext{
${ }^{25}$ Reflexiones del Redactor sobre la instalación del Congreso, 24 de marzo de 1816, In: RAVIGNANI, Emilio (comp.). Asambleas Constituyentes Argentinas. Buenos Aires: UBA, Facultad de Filosofia y Letras, Instituto de Investigaciones Históricas, 1937, t. 1, p. 182. Grifo nosso.
} 
tendências distintas e opostas, mas antes, duas formas diferentes de entender esse conceito e o de construção política. Daí se infere que o papel cumprido pela representação é o de conciliar essas tendências.

O Congresso simboliza a soberania dos povos e seus membros eleitos tanto representam o conjunto desses povos como são a sua possibilidade de expressão. Não seria exagerado afirmar, pois, que as Províncias Unidas do Rio da Prata como construção política encontram sua manifestação mais acabada no Congresso de 1816.

Por esta razão, existe uma competição muito forte entre o Congresso e Buenos Aires, que se vê despojada do papel que cumpria desde 1810. A abundante correspondência do deputado Darregueira oferece várias provas deste estado de ânimo, como revelam por exemplo os extratos seguintes:

La apertura del Congreso va muy despacio. ¡Qué burla amigo tan completa! ¿Qué verguenza que estos miserables pueblos miren con tanto desprecio, en el chasco que nos están dando, la representación de esa gran ciudad y de toda su provincia! No les falta más que mandarnos...

Amante cual ninguno a ese heroico pueblo [Buenos Aires], no consulto sino su opinión por regla de las mías; mas en la sujeta materia [la elección del Director] la llevan otros hasta sacar el gobierno central de allí para conciliar su estabilidad. ¿Qué podremos oponer los diputados de ésa? Cuando sean poderosas nuestras razones ¿de qué sirven contra el torrente de la pluralidad, afianzada en la incontestable verdad de los sacudimientos y continuas revoluciones de la Capital? ${ }^{26}$

No estudo da ação política do Congresso, verifica-se que ele atua como um vínculo entre as cidades e o poder central, ocupando-se dos "assuntos interiores", enquanto o Diretor se encarrega dos "assuntos exteriores", ou seja, da guerra e da diplomacia ${ }^{27}$. No entanto, essa divisão das funções ou, melhor dito, esse ponto de equilíbrio entre as duas tendências, não durará muito. Depois da declaração de independência, o Congresso se encontra submetido à pressão exercida pelo peso crescente da guerra, a ameaça de uma expedição espanhola

\footnotetext{
${ }^{26}$ Cartas de José de Darregueira a don Tomás Guido, 28 de enero y 18 de Abril de 1816, In: GÜEMES, Luis (comp.). Güemes Documentado, Op.cit., t. 3, p. 355 e 365.

${ }^{27}$ Para um estudo completo da atuação do Congresso de Tucumán, cfr. GIANELLO, Leoncio. Historia del Congreso de Tucumán. Buenos Aires: Academia Nacional de la Historia, 1966.
} 
e a de uma invasão portuguesa, etc. Como conseqüência disso, o incendiário Diretor, Juan Martín de Pueyrredón, modifica sua posição, tornando-a mais autoritária e centralizadora e, como resultado, reduz-se a soberania reservada aos povos.

O documento em que se expressa essa nova tendência é o Manifesto de $1^{\circ}$ de agosto, "incitando os povos à união e à ordem". ${ }^{28}$ Nesse texto, o Congresso se apresenta como uma assembléia de sábios localizados num "cume eminente", "dando uma olhada" nos povos, "interrompidos em suas meditações pela incessante agitação tumultuosa que comove [a esses últimos]". Estas palavras nos deixam ver imediatamente que a relação entre o Congresso e os povos havia se modificado: estes últimos já não são considerados como os sujeitos genuínos da soberania. Afinal, as circunstâncias são diferentes: "a revolução toma um novo caráter e o país se apresenta com um aspecto mais funesto". Portanto, não se trata mais de defender os direitos dos povos, e sim de assegurar a salvaguarda do conjunto, tarefa que cabe ao Congresso:

Vosotros provocásteis la creación de una autoridad representativa, que, erigida con el voto universal, formase un punto de unión de todas las relaciones, una expresión de todas las voluntades, una concentración de todos los poderes: vuestras acciones están todas comprometidas en este árbitro soberano de vuestros destinos. (...) El debe fijar límites á la revolución, abrir los senderos del orden, restablecer la armonía, sofocar las aspiraciones, acallar los resentimientos y querellas de los pueblos, y consolidar la unión de las partes dilaceradas. ${ }^{29}$

Esse esforço de consolidação obriga a colocar um fim na revolução, pois "o estado revolucionário não pode ser o estado permanente da sociedade: um estado semelhante declinaria logo em divisão e anarquia e terminaria em dissolução". ${ }^{30}$ Isso repercute por sua vez na questão da delegação de soberania por parte dos povos, o que o texto demonstra minuciosamente:

\footnotetext{
${ }^{28}$ Manifiesto del Congreso de las Provincias unidas de Sudamérica, excitando los pueblos á la unión $\mathrm{y}$ al orden, 10 de agosto de 1816, In: MABRAGANA, H. (comp.). Mensajes de los Gobernantes, 1810-1910. Buenos Aires, s.n., 1910, t. 1, p. 97-110.

${ }^{29}$ Idem, p. 100.

${ }^{30}$ Idem, p. 101.
} 
...abdicar una facultad y retenerla cumulativamente, implica contradicción: inconciliable la una con la otra, sería forzosa la alternativa de destruirse aquélla, si se admitiese ésta; pero un pueblo jamás podrá ser autorizado á romper los vínculos de la convención general. Así, es preciso renunciar á los empeños particulares de cada pueblo ó provincia, y esperar que sus derechos, pretensiones y querellas recíprocas se decidan por la autoridad imparcial irrefragable de la convención general. ${ }^{31}$

Em poucas semanas, o equilíbrio pactuado durante todo o ano de 1815, expresso na abertura do Congresso, foi destruído. Com o Manifesto de $1^{\circ}$ de agosto, produto de um contexto turbulento, se assiste à imposição de uma representação "absoluta" que pretende absorver e assumir por si só toda a soberania que jazia no corpo social.

Esta tendência não irá senão se reforçar com o traslado do Congresso a Buenos Aires, ao fim do ano de 1816. Desde então, as províncias reduzem sua representação, fazendo regressar alguns de seus representantes sob o pretexto - parcialmente verdadeiro - de que não possuem recursos suficientes para pagar sua estadia. Ou seja, os povos não contam mais com a representação para defender seus direitos ou, mais importante ainda, para lhes proporcionar brilho e prestígio. Mas, o que certamente lhes outorga prestígio desde o ano de 1810 é a guerra, e a possibilidade de arvorar os louros da vitória. Por isso, a partir do ano de 1817, tudo parece indicar que a epopéia san martiniana e suas repercussões se revestem de uma importância muito maior que as decisões do Congresso. O traslado da representação a Buenos Aires dá então a sensação de que se abre uma brecha entre dois espaços da revolução: o militar, nos Andes, do qual participam todas as cidades do Interior e o civil, na capital, onde o poder diretor perde pouco a pouco seu crédito e suas forças.

Não obstante, este poder debilitado é o que dará ao novo país a primeira constituição "definitiva", já que todas as precedentes eram concebidas como provisórias $^{32}$. Este texto trata, mais uma vez, de conciliar no seio de um mesmo regime político, as duas tendências opostas que representam os povos, por uma

\footnotetext{
${ }^{31}$ Idem, p. 103. O gri fo é nosso.

${ }^{32}$ Sobre o tema do "provisoriato", cfr. SEGRETI, Carlos. El unitarismo argentino. Op.cit. Cfr. também nosso trabalho, VERDO, Geneviève. Le règne du provisoire: l'élaboration constitutionnelle au Río de la Plata (1810-1820), In : LEMPÉRIÈRE, Annick, ROLLAND, Dennis, MARTINEZ, Frédéric, LOMNÉ, Georges (dir.). L'Amérique Latine face aux modèles européens: emprunts, adpatations, refus, XIXe-XXe siècles. Paris: L'Harmattan, 1998, p. 79-120.
} 
parte, e a nação, por outra. A introdução do bicameralismo tem como intenção explícita equilibrar as forças centrífugas dos povos -representados pela câmara baixa- com a instituição do Senado:

Es indudable que la Camara de Representantes por el origen y cualidades requeridas en sus miembros es un Cuerpo propenso á obrar según las impresiones del espiritu de Pueblo y de Provincia: pero este espiritu particular, centrifugo por su naturaleza, no dejaria de producir á la larga la disolución del Estado, si no fuese moderado y contenido por otro espiritu general y de concentración existente en un Cuerpo, que teniendo siempre por divisa la balanza del interés nacional cuidase de resistir toda medida que no se hubiese pesado en ella, llamando de este modo á un centro comun los intereses y aspiraciones que tirasen a dispersarse. Este Cuerpo como se há visto debe ser el Senado... ${ }^{33}$

Insistimos no caráter particular desse bicameralismo, nada comum nas constituições revolucionárias, dado que a existência de uma câmara única sempre foi vista como a expressão mais acabada da unidade do povo soberano. Este caso, de certa forma bastante parecido ao inglês, funciona de maneira oposta ao caso norte-americano, em que é o Senado que representa os Estados, enquanto a Câmara de Representantes representa o conjunto do povo, ou seja, o conjunto dos cidadãos. No caso das Províncias Unidas, a intenção foi representar as duas formas da soberania a partir de uma perspectiva evolutiva e didática, pois se atribui aos Senadores a missão de "criar um povo", quer dizer, de "nacionalizar a representação", fórmula que não poderia ser mais clara:

Esto hace esperar que los sugetos que sean elevados á aquel rango habran merecido el concepto de la Nación por servicios prestados á toda ella y con los cuales se han hecho conocer y amar de las Provincias, y será un plantel de hombres nacionales que aspirando en sus servicios al credito general de las Provincias, seran siempre los baluartes de la unión, y por consiguiente de la libertad y gloria de todo el Estado. ${ }^{34}$

\footnotetext{
${ }^{33}$ Sesión del Congreso del 12 de diciembre de 1818, In : RAVIGNANI, Emilio (comp.). Asambleas Constituyentes Argentinas. Op.cit., p. 404.

${ }^{34}$ Idem.
} 
Este texto busca assim traduzir constitucionalmente a natureza híbrida que reveste a soberania, conservando por sua vez um governo centralizado. Contudo, a realidade acaba por enfrentar-se com a construção teórica, por mais sofisticada que esta seja. No momento em que a constituição foi jurada pelas cidades do Interior, estas já haviam se desligado da sorte da cidade capital, confundida com o destino do poder diretor.

\section{III - 0 triunfo dos povos}

Já conhecemos o fim da história. A Constituição de 1819, apesar de seus esforços para solucionar o problema do vínculo entre as províncias, revelou-se incapaz de restabelecê-lo. Poucos meses depois de sua promulgação, os acontecimentos militares precipitaram uma vez mais a decomposição do poder central. A invasão de Buenos Aires pelas tropas do Litoral e a derrota de Cepeda, em 1de fevereiro de 1820, provocaram a queda definitiva do Diretório e, com ele, o papel de "cabecera" que a capital havia assumido durante dez anos.

Ao longo dos dez anos que se seguem, no contexto de reorganização do panorama político das Províncias Unidas, assistimos ao mesmo tempo ao triunfo da soberania dos povos e ao esforço por conservar algo dos antigos laços, refundando a unidade sobre a base de uma delegação parcial dos direitos, fórmula que receberá o nome de "federalismo".

O primeiro fato marcante será a criação dos Estados provinciais. ${ }^{35} \mathrm{Em} 1820$, aproveitando o contexto de debilidade máxima do poder central e seguindo o caminho das províncias do Litoral ${ }^{36}$, cada uma das cabeças de intendências (Córdoba, Salta, Tucumán e Mendoza) declara sua independência e se organiza como província autônoma em relação à Buenos Aires, o que dá lugar a declarações formais e a textos constitucionais ${ }^{37}$.

O que é interessante sublinhar é que as cidades cabeceiras atuaram do mesmo modo que Buenos Aires fizera em 1810 e que as cidades espanholas em 1808. Ou seja, as mesmas comunidades que se declaram independentes em nome do retroversão da soberania ao povo, com o pretexto de "reassumir seus direitos"

\footnotetext{
${ }^{35}$ Cf. CHIARAMONTE, José Carlos. “¿Provincias o Estados?”. Op. cit.

${ }^{36}$ Lembramos que as províncias de Entre Rios e Santa Fé vivem desde 1814 em uma situação de quase autonomia, sob a proteção de Artigas.

${ }^{37}$ Para una descrição completa do proceso, ver SEGRETI, Carlos. El país disuelto. El estallido de 1820 y los esfuerzos organizativos. Buenos Aires: Editorial de Belgrano, 1982.
} 
(dos quais supostamente haviam sido despojados pela Coroa espanhola em primeira instância, e a seguir pelo poder central com sede em Buenos Aires), não reconhecem um direito equivalente para as cidades subalternas. O governador de Córdoba, Juan Bautista Bustos, apesar de ser a figura-chave do movimiento federal, disse claramente a seu colega de Catamarca:

La libertad de los pequeños distritos me parece una farsa. Leáse la historia y se verá que ni aun antes del imperio de los Incas, no se encontraron en esta América tribus tan reducidas como en el dia se pretenden. (...) El Congreso [de San Lorenzo] desidira si las ciudades subalternas deben tener su representación en el, o reducirla a uno (sic) por provincia. ${ }^{38}$

O caudilho de Tucumán, Bernabé Aráoz, vai mais longe ainda ao declarar em seu Manifesto de 10 de abril de 1820, dirigido entre outros à cidade de Santiago del Estero:

El lisonjero esplendor del uso libre de vuestros derechos, os deslumbra y alucina hasta el deplorable grado de creeros capaces de entrar por vosotros mismos en un gobierno federal, para lo cual vuestra minoridad e importancia no puede perdonaros... ${ }^{39}$

Entretanto, a aberta hostilidade dos novos chefes não impediu as cidades subalternas de proclamar sua independência, como um efeito da aceleração do processo de "retomada da soberania" por parte dos povos. De fato, entre a primeira etapa e a segunda - a independência das capitais de intendências passaram-se dez anos, ao passo que entre a segunda e a terceira - a emancipação das cidades subalternas - passaram-se nada mais que alguns dias.

O outro aspecto que é preciso sublinhar no proceso de criação dos Estados provinciais é a natureza altamente facciosa do poder, evidenciada pela documentação. Um exemplo encontra-se no manifesto de Abraham González, o novo governador de Tucumán, depois de deposto Bernabé Aráoz:

¿Quién sin risa ha podido ver un congreso compuesto del leguleyo, de un Aráoz presidente, un Aráoz secretario y otro alátere inseparable del

\footnotetext{
38 “Oficio de Bustos a Zisneros, 31 de marzo de 1820", citado por SEGRETI, Carlos. Op.cit., p. 102. 39 “Manifiesto de Bernabé Aráoz del 10 de abril de 1820”. Idem, p. 95.
} 
primero? ¿Cuáles son las leyes, cuáles los establecimientos, cuáles las benéficas disposiciones de esa tan baja alteza? ¿Una constitución sembrada de errores y monstruosidades, no es el monumento más claro de la locura de esos hombres? ${ }^{40}$

E continua em outro documento, a propósito da representação provincial:

Ud. sabe que una representación diminuta, o es una facción, o dista una línea de serlo, y creo que por este principio es que se ha sabiamente doblado la representación provincial de Buenos Aires; sabe Ud. también, que ella no puede subsistir; sino dotada o compuesta de hombres con comodidad, y espíritu público bien grande y sostenido de buenas luces. Supuesto eso, eche la vista sobre esta provincia y si separa al Dr. García asesor de Cabildo, al Dr. Paz, juez de alzadas, al Dr. Molina, que huye de todo asunto de esta clase, y al Dr. Perico Aráoz, no encuentra Ud. más quienes formen el Cuerpo Representativo. ${ }^{41}$

A realidade política dos novos Estados, tal como aparece nesses testemunhos, põe em evidência, por um lado, o número reduzido de homens capazes de ocupar postos políticos e, por outro, a conquista do aparato estatal por meio de redes sociais - familiares, clientelistas - já conformadas. Esta situação, entre outras, permitirá o desenvolvimento do fenômeno do caudilhismo e a coexistência do uso da força com uma ordem legal. ${ }^{42}$

Apesar da força com que se difunde o modelo "federal" de governo nesses anos, a vontade dos Estados provinciais de se manterem unidos em virtude da representação permanece viva e se reveste de um caráter de urgência. Esta constatação demonstra que as duas tendências que analisamos, cujos extremos

\footnotetext{
${ }^{40}$ Manifiesto de Abraham González, 10 de septiembre de 1821, In: GÜEMES, Luis (comp.). Güemes Documentado. Op.cit., t. 11, p. 483-484.

${ }^{41}$ Carta de Abraham González al Gobernador de Buenos Aires, 29 de octubre de 1821, Idem, p. 493.

${ }^{42}$ Sobre esses temas, ver HALPERIN DONGHI, Tulio. El surgimiento de los caudillos en el cuadro de la sociedad rioplatense posrevolucionaria, In: Estudios de Historia Social, no1, Buenos Aires, 1965, p. 121-149; CHIARAMONTE, José Carlos. Legalidad constitucional o caudillismo: el problema del orden social en el surgimiento de los Estados autónomos del Litoral argentino en la primera mitad del siglo XIX, In: America latina dallo stato coloniale allo stato nazione (17501940). Milano: Franco Angeli, 1987, p. 536-556; ROMANO, Sílvia. Usage de la force et ordre légal: Córdoba dans la première moitié du XIXe siècle, In : Histoire et Sociétés de l'Amérique latine, no 5, Paris, 1997, p. 69-93 e GOLDMAN, Noemí e SALVATORE, Ricardo (comp.). Caudillismos rioplatenses. Nuevas miradas a un viejo problema. Buenos Aires: Eudeba, 1998.
} 
seriam a autonomia, de um lado, e a fusão em uma só entidade, de outro, não são tendências opostas e irreconciliáveis, pois estavam presentes dentro de um mesmo projeto político.

Vemos assim o cabildo de Salta postular a união de todas as províncias do antigo Vice-Reino, como único meio de acabar com a guerra e de assegurar uma nova ordem política:

Tucumán, Córdoba, Mendoza, vosotras que estáis más proximas y en una aptitud innegable para cooperar a tan interesante y magnifica obra. Buenos Aires, la Banda Oriental y Paraguay, que podéis también coadyuvar con una generosa profusión. (...) Ejércitos de los Andes y Córdoba; divisiones veteranas y partidas sueltas, que os mantenéis en inacción a costa de los ciudadanos de los territorios que ocupáis; a todos, todos, vuelvo a decir, os convida la provincia de Salta a la ayuda de la empresa del jefe que la preside. ${ }^{43}$

As novas autoridades se esforçam para colocar rapidamente fim aos conflitos que eclodiam entre as cidades, mandando emissários e promovendo a paz a qualquer preço (por exemplo, no caso do confronto entre Buenos Aires e o Litoral, ou entre Salta y Tucumán)..$^{44}$ Mas, sobretudo, assistimos a várias tentativas dos chefes de província para reunir um congresso. O primeiro a fazêlo foi o governador Bustos, sediado em Córdoba, em 3 de fevereiro de 1820. Pouco tempo depois, pelo Pacto do Pilar firmado entre os chefes do Litoral em 23 de fevereiro, as autoridades de Buenos Aires convocam um congresso em São Lourenço. Em julho, Guëmes e o cabildo de Salta, que não podem suportar sozinhos o esforço militar, propõem por sua vez a reunião de um Congresso em Catamarca, com o objetivo de organizar os recursos para a guerra.

Pois bem, dado que já não existia uma "cabeça" que promovesse a união, quer dizer, uma cidade reconhecida como superior às demais e com autoridade suficiente para impor sua decisão, as iniciativas citadas terminam por se contradizer e anular-se e bem poderiam ser entendidas como tentativas para se apoderar da liderança.

\footnotetext{
${ }^{43}$ Acta del Cabildo de Salta del 16 de marzo de 1820, In: GÜEMES, Luis (comp.). Güemes Documentado. Op.cit., t. 9, p. 267.

${ }^{44}$ Cfr. SEGRETI, Carlos. Op.cit.
} 
De todas essas propostas, a que mais peso teve foi a cordobesa. Com efeito, Córdoba se havia colocado como o epicentro da reorganização política sob o modelo federal, e Bustos havia desprendido uma energia considerável para convencer as demais províncias disso. No ano de 1821, os deputados chegam a Córdoba onde o congresso iria se reunir. O objetivo dessa reunião era criar uma confederação para acabar com a guerra e organizar o que finalmente viria a se chamar "a nação".

Contudo, no momento em que o congresso estava prestes a ser aberto, o governador de Buenos Aires, Martín Rodríguez, emitiu um longo manifesto em que expressava as razões pelas quais Buenos Aires se recusava a participar, retirando seus deputados na seqüência. ${ }^{45}$ Em vista das demandas das províncias, as autoridades portenhas mantiveram-se firmes em sua posição. $\mathrm{O}$ argumento usado era o mesmo que lhes serviu durante tantos anos para postergar a promulgação de uma constituição definitiva: antes de pensar em uma organização política duradoura, as províncias tinham de terminar com a guerra, afirmar sua existência, consolidar sua administração interior e desenvolver seus recursos econômicos. Apenas desse modo, poderão se dar conta do interesse de se unir; o congresso, então, "se reunirá sozinho", com o objetivo de criar no novo Estado uma vasta zona de livre comércio.

Dessa forma, podemos ver claramente as novas pretensões do governo de Buenos Aires, já liberado da dura carga de encabeçar o conjunto das províncias envolvendo-se com a guerra: declara-se independente e usufruindo sozinha os produtos da aduana, a antiga cabeça permanecerá isolada e investirá seus recursos em seu própio desenvolvimento provincial.

\section{Conclusão}

A tentativa falida de 1819 se reverterá alguns anos mais tarde, quando as províncias se organizarem por meio de pactos interprovinciais, aos quais Buenos Aires terminará se aliando. Todavia, é importante sublinhar que todos os elementos desse processo já estavam presentes na primera década da revolução da independência. A análise do sujeito soberano e da maneira pela qual se concebe o poder político - centralizado ou autônomo - permite também, em

\footnotetext{
${ }^{45}$ Manifiesto del gobierno de Buenos Aires a las provincias, 19 de septiembre de 1821, In : CARRANZA, Neftali (comp.). Oratoria argentina; discursos, manifiestos y documentos importantes que llegaron a la historia de su patria. La Plata: Sese y Larranaga, 1905, p. 217-228.
} 
nossa opinião, matizar a questão do confronto entre unitários e federalistas, considerando que este deriva de uma perspectiva política comum. Nela coexistem, porém, uma visão mais "moderna" do povo - centralizadora e uniformizadora, típica da modernidade ilustrada - com uma visão mais tradicional, pertencente ao imaginário das comunidades do antigo regime, qual seja, a das autonomias provinciais. Esta última recupera um vigor extraordinário no momento dos acontecimentos revolucionários, não só no caso argentino, mas em todo o mundo hispânico, como mostraram vários autores. ${ }^{46}$

Não obstante, a originalidade do caso argentino é a dificultade para organizar o novo Estado, questão que sempre ficou por se resolver. Nesse marco, vemos atuarem forças contraditórias, centrípetas e centrífugas, as quais permitem entender a natureza e o sentido verdadeiro que teve a fragmentação paulatina da soberania, assim como o papel desempenhado pela representação política.

\section{Referências Bibliográficas}

CAILLET-BOIS, Ricardo (dir.). Mayo Documental. Buenos Aires: UBA, Facultad de Filosofia y Letras, Instituto de Historia Argentina "Emilio Ravignani", 1961, v. 12 , p. 258.

CARRANZA, Adolfo P. (comp.). Archivo General de la República Argentina. Buenos Aires, 1894, tomo 2, p. 222.

CARRANZA, Neftali (comp.). Oratoria argentina; discursos, manifiestos y documentos importantes que llegaron a la historia de su patria. La Plata: Sese y Larranaga, 1905, p. 217-228.

CHIARAMONTE, José Carlos. Ciudadanía, soberanía y representación en la génesis del estado argentino (c. 1810-1852) In: SABATO, Hilda (coord.). Ciudadanía política y formación de las naciones. Perspectivas históricas de América Latina. México: Fondo de Cultura Económica, 1999, p. 94-116.

CHIARAMONTE, José Carlos. Legalidad constitucional o caudillismo: el problema del orden social en el surgimiento de los Estados autónomos del Litoral argentino en la primera mitad del siglo XIX, In: America latina dallo stato coloniale allo stato nazione (1750-1940). Milano: Franco Angeli, 1987, p. 536-556;

CHIARAMONTE, José Carlos. Vieja y nueva representación: los procesos electorales en Buenos Aires, 1820-1820 In: ANNINO, Antonio (coord.). Historia

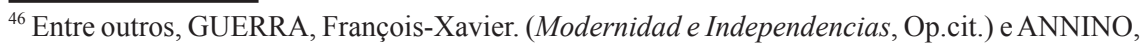
Antonio. Soberanías en lucha, In: GUERRA, François-Xavier, ANNINO, Antonio, CASTRO LEIVA, Luis. Iberoamérica: de los Imperios a las Naciones. Saragoza: Ibercaja, 1994, p. 229-253.
} 
de las elecciones en Iberoamérica, siglo XIX. Buenos Aires: Fondo de Cultura Económica, 1995, p. 19-63.

CHIARAMONTE, José Carlos.¿Provincias o Estados? Los orígenes del federalismo rioplatense In: GUERRA, François-Xavier (dir.). Las revoluciones hispánicas: independencias americanas y liberalismo español. Madrid: Ed. Complutense, 1995, p. 167-205.

COMADRÁN RUIZ, Jorge. Mendoza en 1810 In: Tercer Congreso Internacional de Historia de América. Buenos Aires: Academia Nacional de la Historia, 1961, Tomo 6, p. 287-374.

FREYRE, Ricardo J. (comp.). Tucumán en 1810. Tucumán: s.n., 1909, p. 75.

GIANELLO, Leoncio. Historia del Congreso de Tucumán. Buenos Aires: Academia Nacional de la Historia, 1966.

GOLDMAN, Noemí e SALVATORE, Ricardo (comp.). Caudillismos rioplatenses. Nuevas miradas a un viejo problema. Buenos Aires: Eudeba, 1998.

GÜEMES, Luis (comp.). Güemes documentado. Buenos Aires: Plus Ultra, 1978, t. 2 , p. 367.

GUERRA, François-Xavier, ANNINO, Antonio, CASTRO LEIVA, Luis. Iberoamérica: de los Imperios a las Naciones. Saragoza: Ibercaja, 1994

GUERRA, François-Xavier. Modernidad e independencias. Madrid: Mapfre, 1992.

GUERRA, François-Xavier. The Spanish american tradition of representation and its European roots In: Journal of Latin American Studies, n 26, Cambridge, 1994, p. 1-35.

HALPERIN DONGHI, Tulio. El surgimiento de los caudillos en el cuadro de la sociedad rioplatense posrevolucionaria, In: Estudios de Historia Social, n ${ }^{\circ} 1$, Buenos Aires, 1965, p. 121-149;

LEVENE, Ricardo. Las Provincias Unidas del Sud en 1811: consecuencias inmediatas de la Revolución de Mayo. Buenos Aires: s.n., 1940, Apendice documental, p. 239.

MABRAGANA, H. (comp.). Mensajes de los Gobernantes, 1810-1910. Buenos Aires: s.n., 1910, t. 1, p. 97-110.

MAILLÉ, Agusto E. La Revolución de Mayo a través de los impresos de la época (1809-1815). Buenos Aires: s.n., 1965, v. 2, p. 413.

OZOUF, Mona. L'homme régénéré. Essais sur la révolution française. Paris: Gallimard, 1989.

RAVIGNANI, Emilio (comp.). Asambleas Constituyentes Argentinas. Buenos Aires: UBA, Facultad de Filosofia y Letras, Instituto de Investigaciones Históricas, 1937, t. 1, p. 182.

ROMANO, Sílvia. Usage de la force et ordre légal: Córdoba dans la première moitié du XIXe siècle, In : Histoire et Sociétés de l'Amérique latine, $\mathrm{n}^{\mathrm{o}} 5$, 
Paris, 1997, p. 69-93 e

ROSANVALLON, Pierre. La démocratie inachevée. Histoire de la souveraineté du peuple en France, XIX-XXe siècles. Paris: Gallimard, 2001.

SAMPAY, Arturo E. Las Constituciones de la Argentina (1810-1972). Buenos Aires: Eudeba, 1975, p. 115.

SEGRETI, Carlos. El país disuelto. El estallido de 1820 y los esfuerzos organizativos. Buenos Aires: Editorial de Belgrano, 1982.

SEGRETI, Carlos. El unitarismo argentino. Notas para su estudio en la etapa 1810-1819. Buenos Aires: AZ Editora, 1991, p. 27-29.

VERDO, Geneviève. Le règne du provisoire: l'élaboration constitutionnelle au Río de la Plata (1810-1820), In : LEMPÉRIÈRE, Annick, ROLLAND, Dennis, MARTINEZ, Frédéric, LOMNÉ, Georges (dir.). L'Amérique Latine face aux modèles européens: emprunts, adpatations, refus, XIXe-XXe siècles. Paris: L'Harmattan, 1998, p. 79-120.

VERDO, Geneviève. El precio del poder. Formas e usos de la representación política en la independencia argentina (1810-1821) In: Revista de Indias, Vol. LXII, no 225, maio-agosto, 2002, p. 385-408.

VERDO, Geneviève. Les Provinces 'désunies'du Rio de la Plata. Souveraineté et représentation politique dans l'indépendance argentine (1808-1821). Paris: Universidad de Paris 1, 1998, Cap. 1.

Recebido: abril/2008 - Aprovado: setembro/2008 